\title{
Ginsenoside RK3 Prevents Hypoxia-Reoxygenation Induced Apoptosis in H9c2 Cardiomyocytes via AKT and MAPK Pathway
}

\author{
Jing Sun, ${ }_{1}$ Guibo Sun, ${ }^{1}$ Xiangbao Meng, ${ }^{1}$ Hongwei Wang, ${ }^{2}$ Min Wang, ${ }^{1}$ Meng Qin, ${ }^{1}$ Bo Ma, \\ Yun Luo, ${ }^{1}$ Yingli Yu, ${ }^{1}$ Rongchang Chen, ${ }^{1}$ Qidi Ai, ${ }^{1}$ and Xiaobo Sun ${ }^{1}$ \\ ${ }^{1}$ Key Laboratory of Bioactive Substances and Resources Utilization of Chinese Herbal Medicine, Ministry of Education, \\ Institute of Medicinal Plant Development, Chinese Academy of Medical Sciences \& Peking Union Medical College, \\ Beijing 100193, China \\ ${ }^{2}$ Center for Translational Medicine and Jiangsu Key Laboratory of Molecular Medicine, Medical School of Nanjing University, \\ Nanjing, Jiangsu 210093, China
}

Correspondence should be addressed to Guibo Sun; sunguibo@126.com and Xiaobo Sun; sun_xiaobo163@163.com

Received 8 April 2013; Accepted 13 June 2013

Academic Editor: Ke Liu

Copyright ( 2013 Jing Sun et al. This is an open access article distributed under the Creative Commons Attribution License, which permits unrestricted use, distribution, and reproduction in any medium, provided the original work is properly cited.

Reperfusion therapy is widely utilized for acute myocardial infarction (AMI), but further injury induced by rapidly initiating reperfusion of the heart is often encountered in clinical practice. Ginsenoside RK3 (RK3) is reportedly present in the processed Radix notoginseng that is often used as a major ingredient of the compound preparation for ischemic heart diseases. This study aimed to investigate the possible protective effect of RK3 against hypoxia-reoxygenation (H/R) induced H9c2 cardiomyocytes damage and its underlying mechanisms. Our results showed that RK3 pretreatment caused increased cell viability and decreased levels of LDH leakage compared with the H/R group. Moreover, RK3 pretreatment inhibited cell apoptosis, as evidenced by decreased caspase-3 activity, TUNEL-positive cells, and Bax expression, as well as increased Bcl-2 level. Further mechanism investigation revealed that RK3 prevented H9c2 cardiomyocytes injury and apoptosis induced by H/R via AKT/Nrf-2/HO-1 and MAPK pathways. These observations indicate that RK3 has the potential to exert cardioprotective effects against H/R injury, which might be of great importance to clinical efficacy for AMI treatment.

\section{Introduction}

Acute myocardial infarction (AMI) is the most common cause of death and disability around the world. The pillar of current therapy for AMI is reperfusion to the affected area via thrombolytic therapy or angioplasty. However, reperfusion following ischemia/hypoxia induces further cardiomyocytes death, which is termed ischemia-reperfusion (I/R) injury [1]. Therefore, understanding the basis of reoxygenation and developing a cardioprotective drug that can alleviate the injury induced by $\mathrm{I} / \mathrm{R}$ could maximize the benefits of reoxygenation therapy for AMI.

Although the underlying mechanism regulating myocardial injury induced by $\mathrm{I} / \mathrm{R}$ is still not fully understood, apoptosis is shown to be a highly regulated program of cell death. Apoptosis is initiated shortly after the onset of myocardial infarction and becomes markedly enhanced during reperfusion $[2,3]$. Thus, restraining the cardiomyocyte apoptosis induced by I/R can result in improved prognosis of AMI.

The phosphatidylinositol 3-kinase (PI3K)/AKT and mitogen-activated protein kinases (MAPKs) signaling pathways are known to play pivotal roles in controlling the survival and apoptosis of cardiomyocytes [4-6]. Various studies demonstrated that AKT phosphorylation can activate nuclear factor-erythroid 2- related factor 2 (Nrf-2), which controls the expression of various antioxidant enzymes and Phase II detoxification enzymes such as heme oxygenase-1 (HO-1). HO-1, a subtype of heme oxygenase (HO), plays a central role in cellular antioxidant defense. Many reports have indicated that upregulation of HO-1 mediated by AKT phosphorylation plays an important role in promoting cell survival 


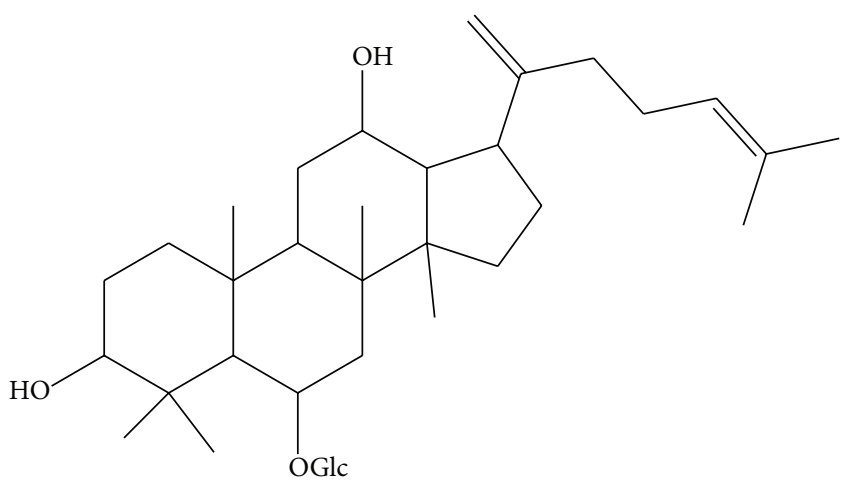

FIGURE 1: Molecular structure of Ginsenoside RK3.

and protecting against H/R injury in cardiomyocytes [79]. Much evidence shows that MAPKs, which include c-Jun $\mathrm{NH}_{2}$-terminal kinases (JNKs), extracellular signal-regulated protein kinase (ERK1/2), and p38 kinases, play critical roles in cells survival and apoptosis during IR injury [10]. The role of the ERK1/2, JNK, and P38 pathway in apoptosis remains controversial, as both proapoptotic and antiapoptotic effects have been observed dependenting on cell type and apoptotic stimuli [11-14].

Radix notoginseng are frequently used in the prevention and treatment of cardiovascular diseases in China and other Asian countries. Panax notoginseng saponins (PNS), including notoginsenoside R1, ginsenosides Rg1, Rb1, Rh2, and RK3, are generally believed to be the main active components responsible for the claimed efficacy [15-18]. Ginsenoside RK3 (RK3) is reportedly present in the processed Radix notoginseng herbs [19]. Previous experiments showed that RK3 possesses immunomodulatory, antiplatelet aggregating, and antiproliferative activity [20-22]. However, little is known about the possible cardioprotective effect of RK3. Therefore, exploring the potential cardioprotective effect of RK3 and its underlying mechanisms is of great interest.

\section{Materials and Methods}

2.1. Materials. Ginsenoside RK3 (molecular weight $=620$; purity > 98\%) was purchased from Shanghai Winherb Medical S\&T Development (Shanghai, China). The molecular structure of RK3 is shown in Figure 1. Rat embryonic cardiomyoblast-derived H9c2 cardiomyocytes were obtained from the Cell Bank of the Chinese Academy of Sciences (Shanghai, China). All cell culture materials were from GIBCO (Grand Island, NY). The Cell Counting Kit-8 was purchased from Dojindo laboratory (Japan). Caspase-3 fluorometric and ROS fluorometric assay kits were acquired from BioVision (CA, USA). The kits for determining lactate dehydrogenase $(\mathrm{LDH})$ were purchased from Nanjing Jiancheng Institute of Biological Engineering (Nanjing, China). All antibodies were purchased from Santa Cruz Biotechnology (Santa Cruz, CA), and other chemicals were purchased from Sigma (St. Louis, MO).
2.2. Cell Culture and Hypoxia-Reoxygenation. H9c2 cardiomyocytes were cultured in high glucose DMEM supplemented with $10 \%(\mathrm{v} / \mathrm{v})$ fetal bovine serum, $1 \%$ penicillin/streptomycin (v/v), and $2 \mathrm{mM}$ L-glutamine. The cells were maintained at $37^{\circ} \mathrm{C}$ with $100 \%$ relative humidity in a $\mathrm{CO}_{2}$ incubator containing $5 \% \mathrm{CO}_{2}$ at $37^{\circ} \mathrm{C}$. High glucose DMEM medium was changed with none glucose DMEM to mimic ischemia. Then the $\mathrm{H} 9 \mathrm{c} 2$ cardiomyocytes were incubated at $37^{\circ} \mathrm{C}$ in an anaerobic glove box (Coy Laboratory, USA), from which normal air was removed by a vacuum pump and replaced with $5 \% \mathrm{CO}_{2}, 5 \% \mathrm{H}_{2}$, and $90 \% \mathrm{~N}_{2}$. The $\mathrm{H} 9 \mathrm{c} 2$ cardiomyocytes were cultured under hypoxia for $6 \mathrm{~h}$. Then the cells were removed from the anaerobic glove box, and the medium was replaced with high glucose medium and maintained in the regular incubator to mimic reperfusion. The corresponding control cells were incubated under normoxic conditions for equivalent durations with high glucose DMEM. For all experiments, cells were plated at an appropriate density according to the experimental design and were grown for $24 \mathrm{~h}$ to reach $70 \%-80 \%$ confluence before experimentation.

2.3. Analysis of Cytotoxicity. Cytotoxicity was determined by two alternative methods: gross detection of cell viability by Cell Counting Kit-8 (CCK8) assay and cell death by LDH assay. In cell viability assay, $\mathrm{H} 9 \mathrm{c} 2$ cardiomyocytes were seeded at $1 \times 10^{4}$ cells/well in 96-well plates. After $6 \mathrm{~h}$ of hypoxia treatment, cell viability was determined at $0,2,4,8,12$, and $24 \mathrm{~h}$ after reoxygenation according to the CCK8 assay kit protocol. Briefly, $10 \mu \mathrm{L}$ of CCK 8 solution was added to the culture medium. Optical density was measured at $450 \mathrm{~nm}$ wavelength and afterwards incubated for an additional $2 \mathrm{~h}$, using a microplate reader (SpectraFluor, TECAN, Sunrise, Austria). Next, prior to H/R treatment, the cells were incubated with different concentrations of RK3 $(6.25,12.5,25$, and $50 \mu \mathrm{g} / \mathrm{mL}$ ) for $12 \mathrm{~h}$, and then cell viability was evaluated as mentioned earlier.

Cell death was evaluated by $\mathrm{LDH}$ method. Briefly, H9c2 cardiomyocytes were cultured at $2 \times 10^{5}$ cells/well in 6well plates for $24 \mathrm{~h}$. After $\mathrm{H} / \mathrm{R}$ treatment with or without RK3 $(25 \mu \mathrm{g} / \mathrm{mL})$ pretreatment, the medium was collected to measure $\mathrm{LDH}$ release using $\mathrm{LDH}$ assay kits, following manufacturer instructions.

2.4. Analysis of Caspase-3 Activation. The activation of caspase- 3 was determined using a fluorescein active caspase3 staining kit (BioVision), following the instructions supplied by the manufacturer. Briefly, H9c2 cardiomyocytes were collected after H/R treatment with or without RK3 $(25 \mu \mathrm{g} / \mathrm{mL})$ pretreatment and then incubated on ice with $50 \mu \mathrm{L}$ chilled lysate buffer for $10 \mathrm{~min}$. Next, $50 \mu \mathrm{L}$ of $2 \mathrm{x}$ reaction buffer (containing $10 \mathrm{mM}$ dithiothreitol) and $5 \mu \mathrm{L}$ of caspase- 3 substrate (DEVD-AFC, $1 \mu \mathrm{M}$ ) were added to each sample. The specimens were then incubated at $37^{\circ} \mathrm{C}$ for $2 \mathrm{~h}$. Caspase3 activity was determined by measuring fluorescence at an excitation wavelength of $380 \mathrm{~nm}$ and an emission wavelength of $440 \mathrm{~nm}$ (SpectraFluor, TECAN, Sunrise, Austria). 
2.5. Hoechst 33342 and PI Double Staining. In this study, cells were double-stained with Hoechst 33342 and propidium iodide (PI) for the qualitative analysis of apoptosis. H9c2 cardiomyocytes were cultured in 24 -well plates for $24 \mathrm{~h}$. After treatment, cells were washed twice with phosphate-buffered saline (PBS) and incubated with $10 \mu \mathrm{g} / \mathrm{mL}$ Hoechst 33342 dye for $15 \mathrm{~min}$ at $37^{\circ} \mathrm{C}$ in the dark, and then $100 \mu \mathrm{g} / \mathrm{mL}$ propidium iodide was added (PI, Sigma). Stained nuclei were observed immediately, using a fluorescence microscopy (Leica, Germany Q9). In normal cells, the nuclei appeared intact and even stained in blue by Hoechst 33342, whereas cells with bright blue or red/pink nuclei were considered apoptotic cells [23].

2.6. Terminal Deoxynucleotidyl Transferase-Mediated dUTP Nick End Labeling (TUNEL) Staining. Terminaldeoxynucleotidyl-transferase- (TdT-) mediated desoxyuridinetriphosphate (dUTP) nick end labelling (TUNEL) was used in apoptosis detection. Briefly, H9c2 cardiomyocytes were cultured in 24-well plates for $24 \mathrm{~h}$. After exposure to hypoxia for $6 \mathrm{~h}$ and reoxygenation for $24 \mathrm{~h}$, H9c2 cardiomyocytes were fixed by incubation in $10 \%$ neutral buffered formalin solution for $30 \mathrm{~min}$ at room temperature. H9c2 cardiomyocytes were incubated for $30 \mathrm{~min}$ with a methanol solution containing $0.3 \% \mathrm{H}_{2} \mathrm{O}_{2}$ to stop the activity of endogenous peroxidase. $\mathrm{H} 9 \mathrm{c} 2$ cardiomyocytes were treated with a permeabilizing solution $(0.1 \%$ sodium citrate and $0.1 \%$ Triton X-100) for $2 \mathrm{~min}$ at $4^{\circ} \mathrm{C}$ and then incubated in the TUNEL reaction mixture for $60 \mathrm{~min}$ at $37^{\circ} \mathrm{C}$. Morphological analysis was performed through fluorescence microscopy (DM4000B, Leica, Wetzlar, Germany). Four fields were randomly selected from each sample, and at least 100 cells were counted to calculate the apoptosis rate.

2.7. Preparation of Cell Lysates for Western Blotting. H9c2 cardiomyocytes were pretreated with RK3 $(25 \mu \mathrm{g} / \mathrm{mL})$ for $12 \mathrm{~h}$. The cells were harvested after $\mathrm{H} / \mathrm{R}$, washed once with PBS, and then the cytoplasmic and nuclear fractions were lysed by commercially available cytoplasmic extraction reagents on ice. The supernatants were collected, assayed for protein concentration using bicinchoninic acid assay, and stored at $-80^{\circ} \mathrm{C}$ until their use in Western blot analysis.

2.8. Western Blot Analysis. Equal amounts $(10 \mu \mathrm{g})$ of protein fractions were separated by electrophoresis on $10 \%$ sodium dodecyl sulfate polyacrylamide gels (SDS-PAGE), in which the protein samples were evenly loaded. The proteins were then transferred onto nitrocellulose membranes in Trisglycine buffer at $110 \mathrm{~V}$ for $1 \mathrm{~h}$. The membranes were blocked with $5 \%(\mathrm{w} / \mathrm{v})$ nonfat milk powder in Tris-buffered saline containing $0.1 \%(\mathrm{v} / \mathrm{v})$ Tween-20 (TBST) and then incubated overnight with appropriate primary antibodies at $4^{\circ} \mathrm{C}$. Afterwards, they were washed thrice with TBST and incubated with secondary antibodies for $2 \mathrm{~h}$ at room temperature. The results were visualized by enhanced chemiluminescence.

2.9. Statistical Analyses. The results were expressed as means \pm standard deviation. All statistical analyses were performed through Student $t$-test or analysis of variance (ANOVA) with Prism 5.00 software. Statistical significance was considered at $P<0.05$. All data were performed in at least three independent experiments.

\section{Results}

3.1. Effect of H/R on Cell Viability and Cell Death in H9c2 Cardiomyocytes. In order to study whether RK3 was able to protect against cardiac injury induced by $H / R$ in vitro, we first determined the reoxygenation conditions leading to cell toxity in $\mathrm{H} 9 \mathrm{c} 2$ cardiomyocytes. Cells were exposed to hypoxia for $6 \mathrm{~h}$, followed by reoxygenation for $24 \mathrm{~h}$. Then, cell viability was detected at $0,2,4,8,12$ and $24 \mathrm{~h}$ after reoxygenation by CCK 8 assay. The cells in control group were considered $100 \%$ viable. As shown in Figure 2(a), $6 \mathrm{~h}$ of hypoxia caused a decrease of approximately $25.46 \%$ in cell viability, and reoxygenation provoked further decline in cell viability by a time-dependent manner. The viability of cardiomyocytes at $24 \mathrm{~h}$ after reoxygenation was around $51.17 \%$.

LDH leakage, as a biomarker of cell death, was also detected at different times of reoxygenation. As shown in Figure 2(b), reoxygenation induced further release of LDH compared to hypoxia groups. LDH leakage increased quickly at $0 \mathrm{~h}$ to $4 \mathrm{~h}$ after reoxygenation and reached a peak at $24 \mathrm{~h}$. Based on the results previous, hypoxia for $6 \mathrm{~h}$ and reoxygenation for $24 \mathrm{~h}$ were selected as optimal conditions for the following experiments.

3.2. Effect of $H / R$ on Cell Apoptosis in H9c2 Cardiomyocytes. $\mathrm{H} 9 \mathrm{c} 2$ cardiomyocytes were exposed to hypoxia for $6 \mathrm{~h}$, and caspase-3 activity, a biomarker of apoptosis, was detected at different times after reoxygenation to assess whether this cytotoxic effect was connected with apoptosis to some extent. As shown in Figure 3(a), the reoxygenation induced activation of caspase- 3 , which started at $2 \mathrm{~h}$ after reoxygenation and reached an activation peak at $24 \mathrm{~h}$. This result indicated that cardiac myocyte apoptosis contributed to myocardial H/R injury.

The morphological changes in apoptotic $\mathrm{H} 9 \mathrm{c} 2$ cardiomyocytes induced by $\mathrm{H} / \mathrm{R}$ were observed through Hoechst 33342/PI staining. Cells with blue nuclei were considered normal, while cells with bright blue or red/pink nuclei were considered apoptotiosis. As shown in Figure 3(b), few cells with nuclear staining bright blue or red/pink were observed in the control group. After being exposed to hypoxia for $6 \mathrm{~h}$, about $11.16 \%$ of cells showed apoptosis characteristics. Reoxygenation significantly increased the percentage of the apoptotic cells in a time-dependent manner compared with the groups that accepted hypoxia alone, as shown in Figure 3(c).

\subsection{Effect of $H / R$ on $A K T$ and MAPK Signaling Pathways in} H9c2 Cardiomyocytes. We examined the protein expression of total and phosphorylated (active form) AKT and three major constituents of the MAPK signaling cascade, ERK1/2, JNK, and p38 at different times $(0 \mathrm{~h}$ to $48 \mathrm{~h})$ to elucidate the molecular mechanism of $\mathrm{H} / \mathrm{R}$-induced apoptosis in $\mathrm{H} 9 \mathrm{c} 2$ 


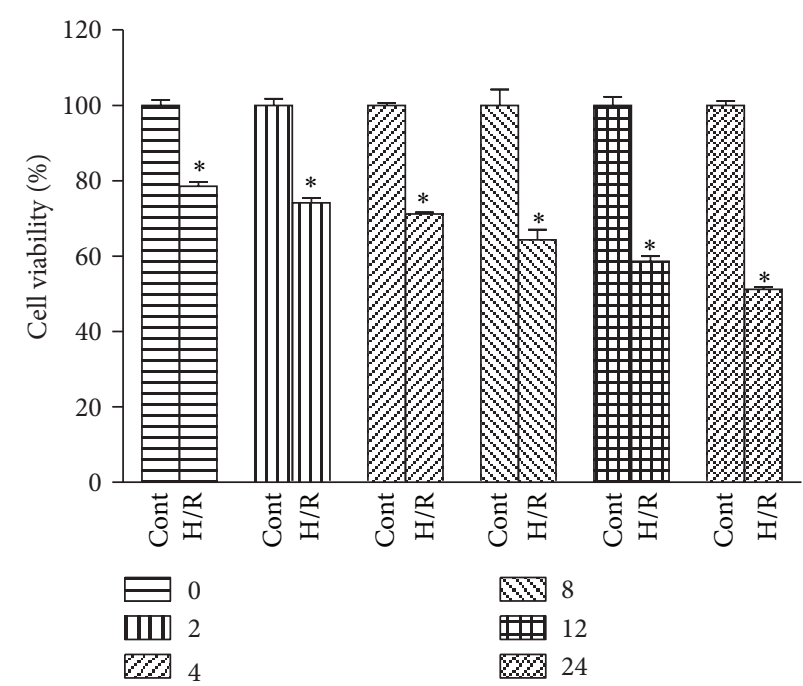

(a)

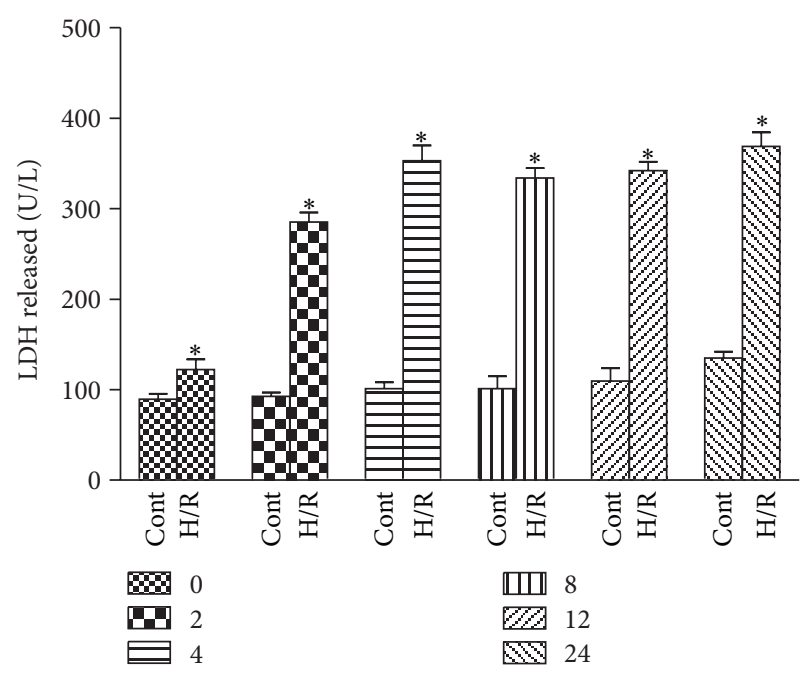

(b)

FIGURE 2: Effects of H/R on cell viability and LDH release in $\mathrm{H} 9 \mathrm{c} 2$ cardiomyocytes. H9c2 cardiomyocytes were exposed to $6 \mathrm{~h}$ of hypoxia, followed by $24 \mathrm{~h}$ of reoxygenation. Then, cell viability was detected at $0,2,4,8,12$, and $24 \mathrm{~h}$ after reoxygenation using CCK8 assay (a). Cell death was also measured by $\mathrm{LDH}$ assay kit (b). The results are represented as means $\pm \mathrm{SD}$ from three independent experiments. ${ }^{*} P<0.05$ versus control group.

cardiomyocytes. As shown in Figure 4, phosphorylation of AKT, ERK1/2, JNK, and p38 was markedly induced after hypoxia. Increased p-AKT, p-JNK, and p-p38 remained active until $48 \mathrm{~h}$ after reoxygenation (Figures 4(a), 4(c), and 4(d)). By contrast, p-ERK1/2 decreased quickly after reoxygenation (Figure 4(b)). Total ERK1/2, JNK, and p38 protein levels did not change during $\mathrm{H} / \mathrm{R}$ exposure. These results indicate that H/R-induced apoptosis in H9c2 cardiomyocytes was accompanied by a quick but transient increase in p-ERK1/2 and sustained/delayed increase in p-JNKs and p-p38 as well as p-AKT.

3.4. RK3 Protects H9c2 Cardiomyocytes from H/R-Induced Cytotoxicity. Before testing the role of RK3 on protection against H/R-induced cell damage, we first analyzed the direct effect of RK3 on H9c2 cardiomyocytes. To this end, cells were treated for $12 \mathrm{~h}$ with RK3 in concentrations ranging from $6.25 \mu \mathrm{g} / \mathrm{mL}$ to $50 \mu \mathrm{g} / \mathrm{mL}$. As shown in Figure 5(a), cell viability revealed no difference between RK3-treated and control groups, demonstrating that none of the tested concentrations of RK3 induced cell injury in H9c2 cardiomyocytes.

H9c2 cardiomyocytes were pretreated with RK3 $(6.25 \mu \mathrm{g} / \mathrm{mL}$ to $50 \mu \mathrm{g} / \mathrm{mL})$ for $12 \mathrm{~h}$ then further exposed to $\mathrm{H} / \mathrm{R}$. Viability was measured to assess whether treatment with RK3 repressed the cytotoxic effect induced by $\mathrm{H} / \mathrm{R}$. The results showed that pretreatment with RK3 $(6.25 \mu \mathrm{g} / \mathrm{mL}$ to $25 \mu \mathrm{g} / \mathrm{mL}$ ) increased cell viability in a dose-dependent manner. Higher RK3 concentration (up to $50 \mu \mathrm{g} / \mathrm{mL}$ ) did not improve cell viability (Figure 5(b)).

In addition, Figure 5(c) showed that pretreatment of cells with RK3 could prevent the appearance of H/R-induced cell death in all the concentrations tested. Treating cells with RK3 $(6.25 \mu \mathrm{g} / \mathrm{mL}$ to $25 \mu \mathrm{g} / \mathrm{mL})$ protected against H/R-induced cell death in a dose-dependent manner. Higher concentration (up to $50 \mu \mathrm{g} / \mathrm{mL}$ ) no longer decreased LDH release. Therefore, all subsequent experiments were performed with $25 \mu \mathrm{g} / \mathrm{mL}$ of RK3.

3.5. RK3 Protects H9c2 Cardiomyocytes from H/R-Induced Cell Apoptosis. TUNEL staining and fluorescence detection of caspase-3 were used in H9c2 cardiomyocytes to confirm whether the protection function of RK3 was connected to apoptosis. As shown in Figure 6(a), H/R-treated H9c2 cardiomyocytes resulted in significant internucleosomal DNA fragmentation. By contrast, pretreatment with RK3 $(25 \mu \mathrm{g} / \mathrm{mL})$ effectively ameliorated the H/R-induced DNA fragmentation. The percentage of TUNEL-positive cells was also calculated, as presented in Figure 6(b). RK3 pretreatment also consistently suppressed the activation of caspase3 induced by H/R (Figure 6(c)). These results indicate that $\mathrm{RK} 3$ can protect $\mathrm{H} 9 \mathrm{c} 2$ cardiomyocytes from $\mathrm{H} / \mathrm{R}$-induced cell apoptosis.

3.6. Effect of RK3 Treatment on H/R-Induced Alterations of Bax and Bcl-2 Proteins in H9c2 Cardiomyocytes. To investigate whether RK3 could modulate the expression of antiapoptotic Bcl-2 and proapoptotic Bax proteins, Western blot analysis was performed in $\mathrm{H} 9 \mathrm{c} 2$ cardiomyocytes exposed to H/R. As shown in Figure 7(a), H/R treatment resulted in a decrease in $\mathrm{Bcl}-2$ protein and an increase in Bax protein compared with control cells.

However, pretreatment with RK3 blocked these changes. Furthermore, the decrease of the Bcl-2-to-Bax ratio in $\mathrm{H} 9 \mathrm{c} 2$ cardiomyocytes exposed to $\mathrm{H} / \mathrm{R}$ was enhanced by $\mathrm{RK} 3$ treatment (Figure 7(b)). These findings suggest that RK3 can enhance I/R-induced apoptosis via regulating the expression of Bcl-2 family proteins. 


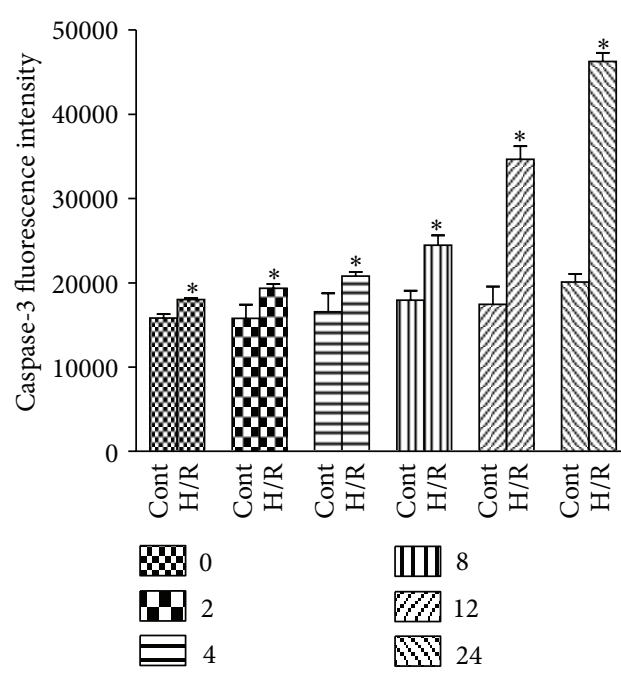

(a)

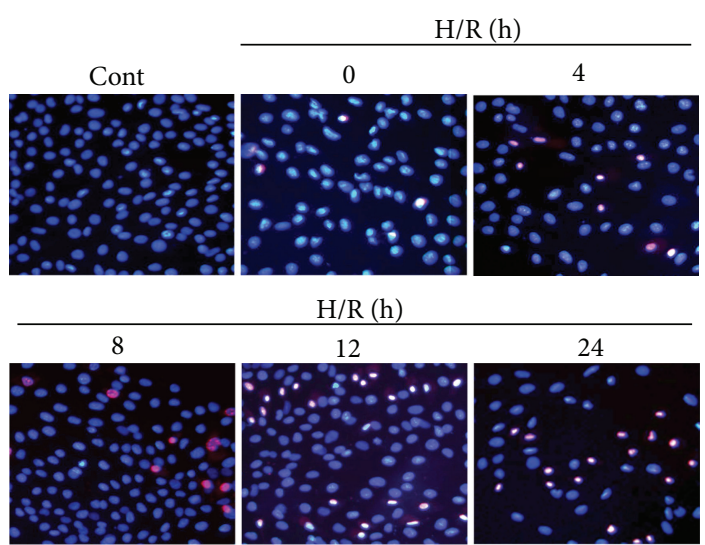

(b)

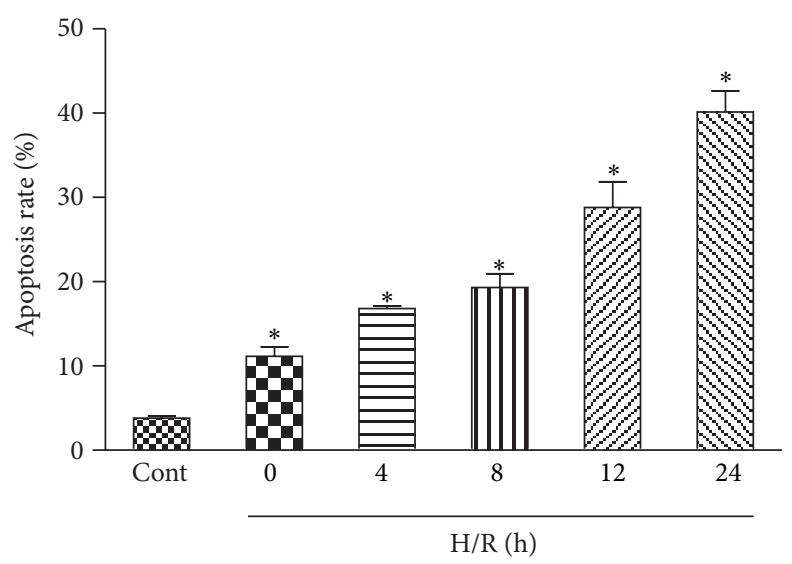

(c)

Figure 3: Effects of H/R on apoptosis in H9c2 cardiomyocytes. H9c2 cardiomyocytes were exposed to 6 h of hypoxia followed by 24 h of reoxygenation. Then, the caspase-3 activity (units per microgram of protein) was assayed, as described in Section 2, at 0,2, 4, 8, 12, and 24 $\mathrm{h}$ after reoxygenation (a). Hoechst 33342 and PI double staining were also used in the qualitative and quantitative analyses of the apoptotic cells $(\mathrm{b}$ and $\mathrm{c})$. The results are represented as means $\pm \mathrm{SD}$ from three independent experiments. ${ }^{*} P<0.05$ versus control group.

3.7. Involvement of AKT Signaling Transduction Pathway and RK3 in H/R-Induced Caspase-3 Activation and Cytotoxicity. The combined PI3K/AKT-Nrf2/HO-1 signaling transduction pathways reportedly play a key role in protecting cells against the toxicity caused by $\mathrm{H} / \mathrm{R}$. Thus, we were prompted to evaluate whether RK3 would affect H/R-induced AKT phosphorylation and subsequent Nrf-2 nuclear translocation and $\mathrm{HO}-1$ upregulation in $\mathrm{H} 9 \mathrm{c} 2$ cardiomyocytes. As shown in Figure 8(a), RK3 pretreatment increased the protein level of p-AKT significantly, compared with either the control group or the H/R group. Consonantly, H/R slightly upregulated the expressions of HO-1, as well as the accumulation of the nuclear factor Nrf2. Pretreatment of RK3 markedly upregulated the HO-1 and Nrf-2 expressions in cardiomyocytes compared with the control and H/R groups.

The effect of RK3 on the combined PI3K/AKT-Nrf2/HO-1 signaling transduction pathways was further confirmed using a PI3K/AKT inhibitor LY294002 and an inhibitor of HO1 activity (ZnPP). As shown in Figure 8(b), pretreatment of
H9c2 cardiomyocytes with LY294002 significantly increased the expression of caspase- 3 and inhibited the upregulation of HO-1 compared with RK3 treatment groups. Furthermore, LY294002 or ZnPP could attenuate the RK3-mediated cardioprotection indicated by decreased cell viability as shown in Figures $8(\mathrm{c})$ and $8(\mathrm{~d})$. These results suggest that RK3 mediates its cardioprotective effect through the activation of the combined $\mathrm{PI} 3 \mathrm{~K} / \mathrm{AKT} / \mathrm{Nrf} 2 / \mathrm{HO}-1$ signaling transduction pathways in $\mathrm{H} 9 \mathrm{c} 2$ cardiomyocytes.

3.8. Involvement of ERK1/2, JNK, p38, and RK3 on $H / R$ Induced Caspase-3 Activation and Cytotoxicity. Accumulated evidence indicates that the MAPK signaling pathways, including the ERK1/2, JNK, and p38 MAPK, play a major role in the apoptosis processes induced by H/R. The expression levels of both total and phosphorylated proteins were evaluated through immunoblotting assay to determine the involvement of the MAPK signaling pathways. As shown in Figure 9(a), RK3 pretreatment increased the protein level of 

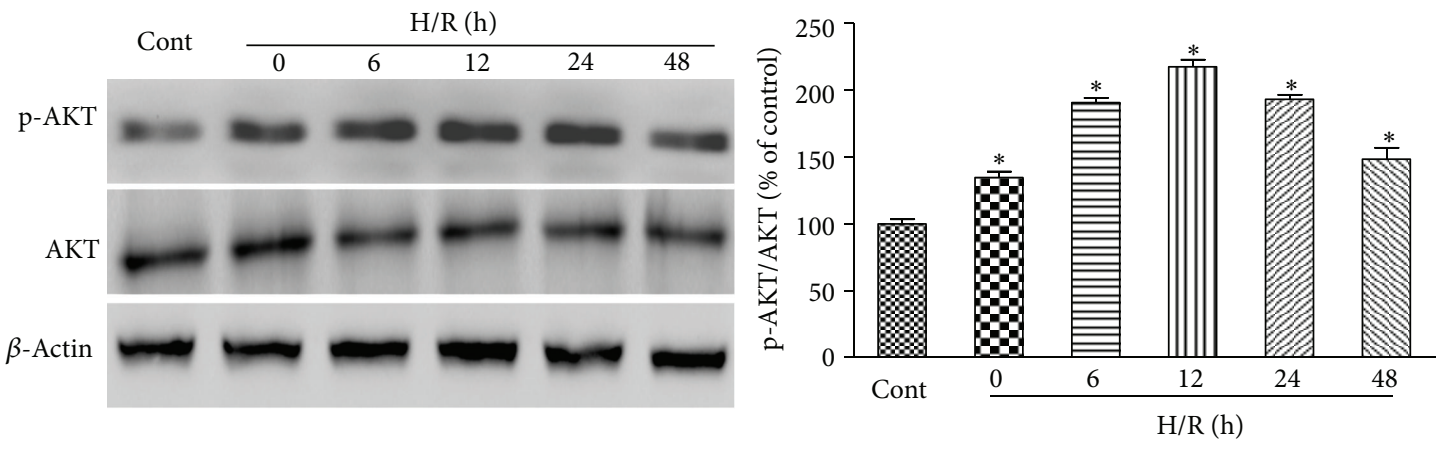

(a)
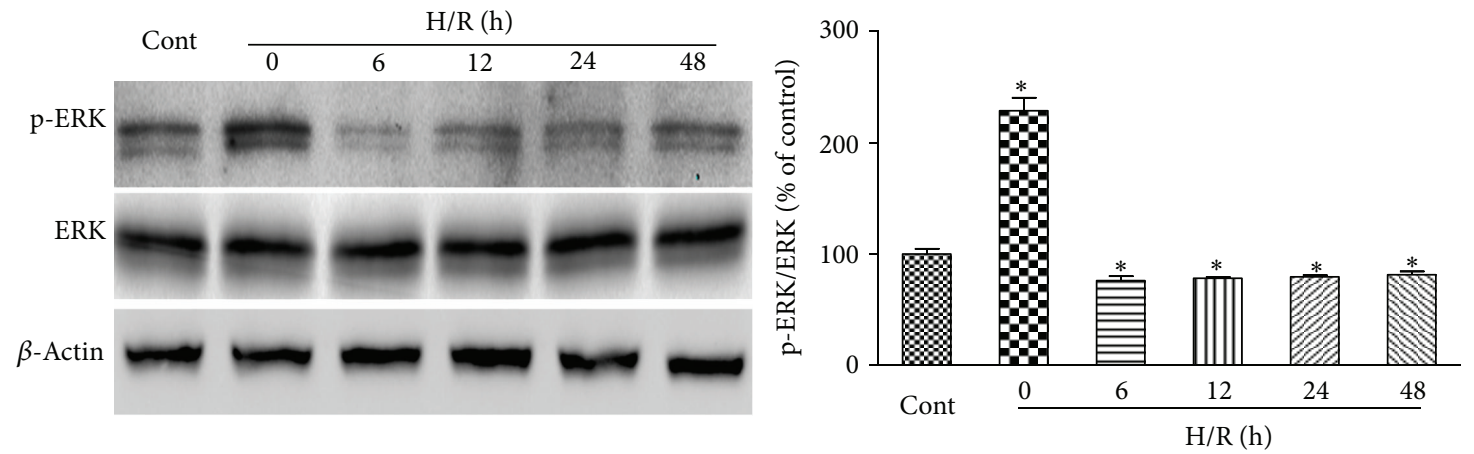

(b)
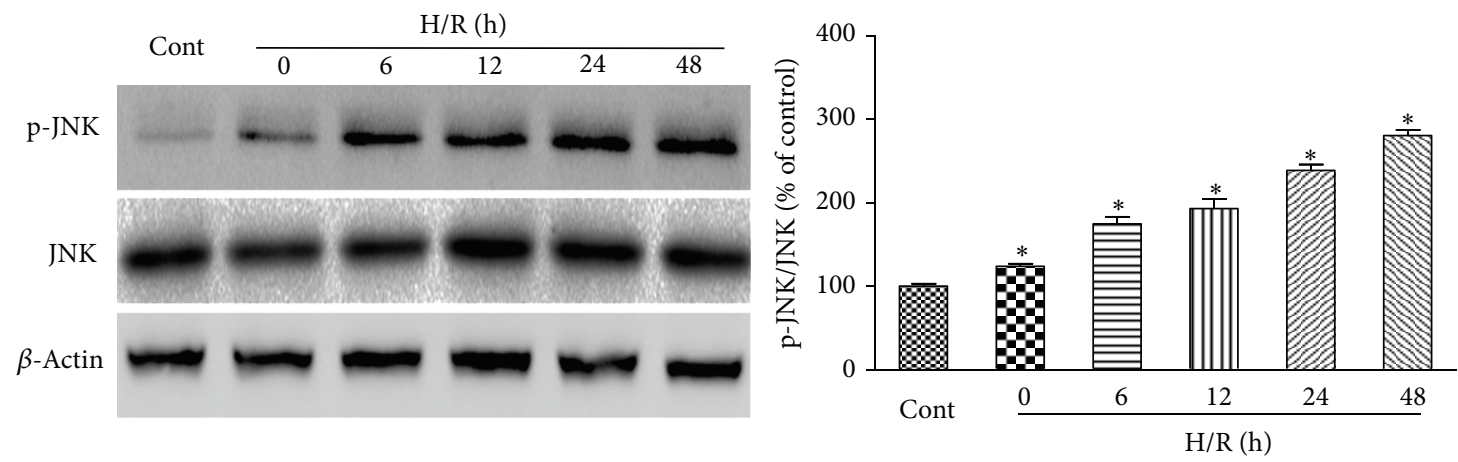

(c)
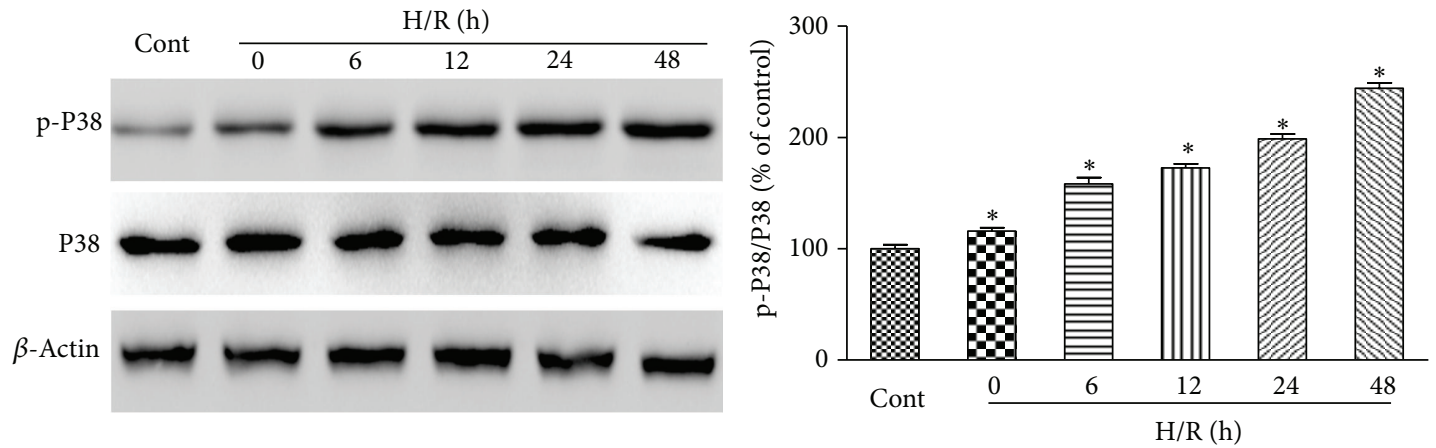

(d)

Figure 4: Effects of H/R on AKT and MAPK signaling pathways in H9c2 cardiomyocytes. H9c2 cardiomyocytes were exposed to $6 \mathrm{~h}$ of hypoxia followed by $48 \mathrm{~h}$ reoxygenation. Then the expression levels of phosphorylated and total AKT (a), ERK1/2 (b), JNK (c), and p38 (d) were detected by immunoblotting assay at $0,6,12,24$, and $48 \mathrm{~h}$ after reoxygenation. The percentage values of the p-AKT/AKT, p-ERK1/2/ERK1/2, $\mathrm{p}-\mathrm{JNK} / \mathrm{JNK}$, and p-p38/p38 ratios relative to the control condition are shown. Normalization of Western blots was ensured by $\beta$-actin. The results are represented as means $\pm \mathrm{SD}$ from three independent experiments. ${ }^{*} \mathrm{P}<0.05$ versus control group. 


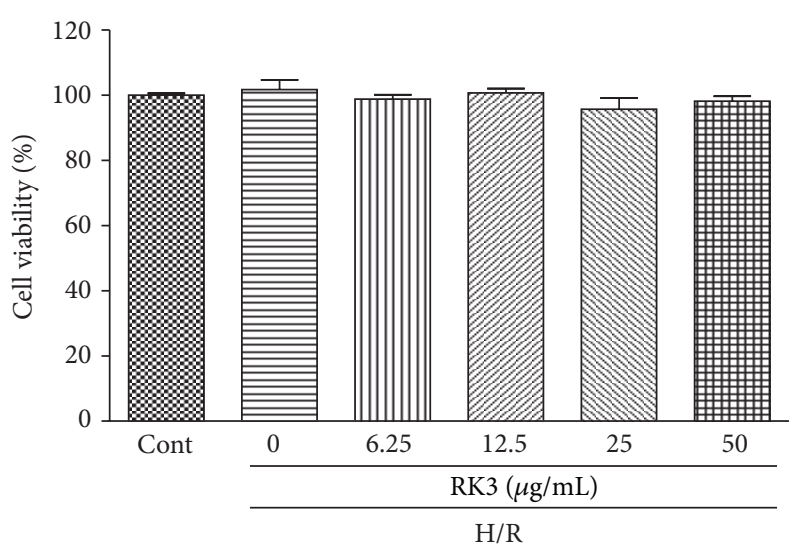

(a)

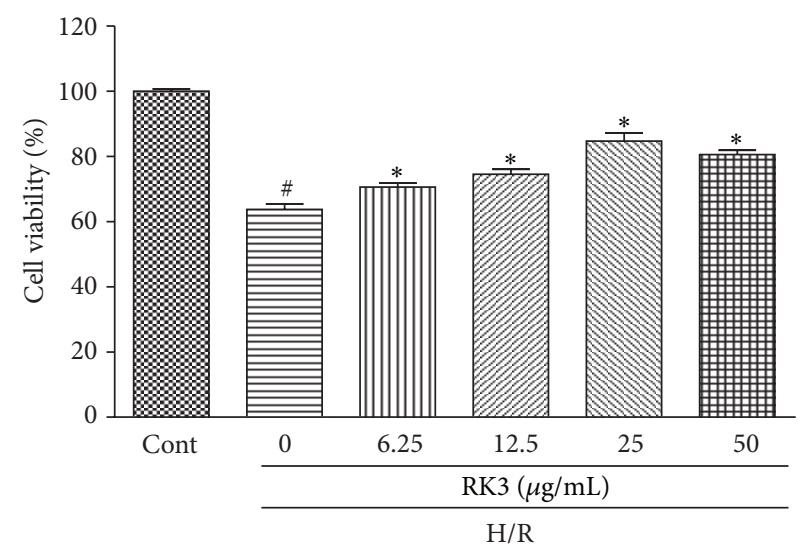

(b)

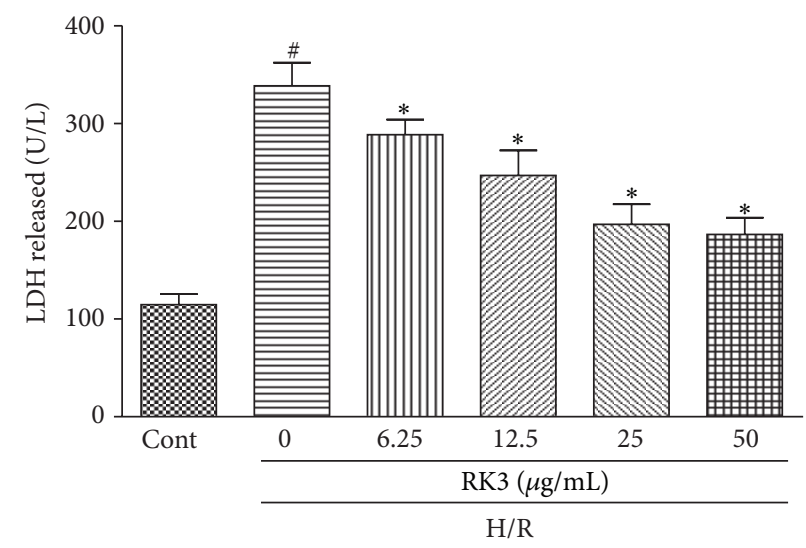

(c)

FIGURE 5: Effects of RK3 on cell viability and LDH release. H9c2 cardiomyocytes were coincubated with different concentrations of RK3 $(6.25,12.5,25$, and $50 \mu \mathrm{g} / \mathrm{mL})$ for $12 \mathrm{~h}$. Cell viability was determined by CCK8 assay and expressed as a relative percentage of control group (a). Control and RK3-treated cells were further exposed to $6 \mathrm{~h}$ of hypoxia followed by $24 \mathrm{~h}$ reoxygenation. Cell viability (b) and LDH release (c) were measured. The results are represented as means \pm SD from three independent experiments. ${ }^{\#} P<0.05$ versus control group; ${ }^{*} P<0.05$ versus $\mathrm{H} / \mathrm{R}$-treated cells.

phosphorylated ERK1/2 in H9c2 cardiomyocytes, compared with the H/R group. By contrast, pretreatment with RK3 significantly inhibited the expression of p-JNK and p-p38 induced by $\mathrm{H} / \mathrm{R}$.

Furthermore, pretreatment of PD98059 (an ERK-specific inhibitor) attenuated the RK3-mediated cardioprotection. However, pretreatment of SB203580 (a p38-specific inhibitor) or SP98059 (a JNK-specific inhibitor) reduced H/R-induced decline of cell viability and capase-3 activation. (Figures 9(b), 9(c), and 9(d)). All these results indicate that the MAPKs signaling pathway was involved in the antiapoptotic and cytoprotection effect of RK3.

\section{Discussion}

Despite advancements in the pharmacologic and early revascularization therapies over the past two decades, AMI remains a leading cause of death in worldwide epidemics. A major reason for this situation is $I / R$ injury. As with reperfusion, reoxygenation does not completely reverse the hypoxia-induced changes but causes further cardiomyocyte damage [24]. Experimental animal models and pathologic studies in humans show that apoptosis may be responsible for AMI and I/R injury and involved in postinfarction remodeling. In addition, apoptosis is always an important research direction for therapeutic application in AMI since the first description of apoptosis in this pathological process [25-27].

$\mathrm{RK} 3$ is reportedly present in Radix notoginseng which is generally used as a major ingredient of compound preparation such as Compound Danshen Tablets, used to treat ischemic heart diseases [28]. In this study, we first demonstrated that RK3 can protect H/R-induced H9c2 cardiomyocytes injury. The underlying mechanisms of this protective effect of RK3 are proven to involve AKT and MAPK pathways.

In present study, we first validated that $\mathrm{H} / \mathrm{R}$-induced cell damage in $\mathrm{H} 9 \mathrm{c} 2$ cardiomyocytes was associated with apoptosis by activation of caspase-3, which is considered a very specific and sensitive apoptotic marker [29]. The morphological changes of apoptotic H9c2 cardiomyocytes induced by $\mathrm{H} / \mathrm{R}$ were observed by Hoechst 33342/PI staining. 

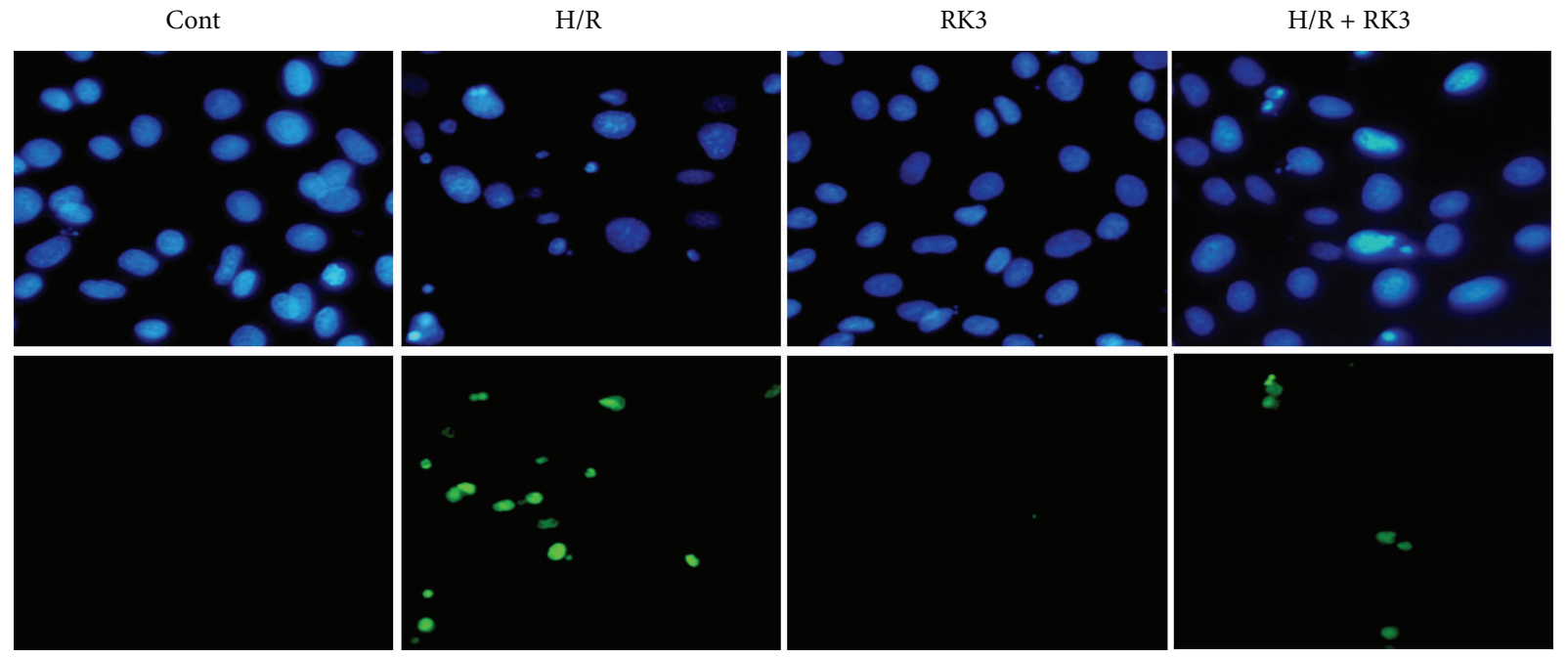

(a)

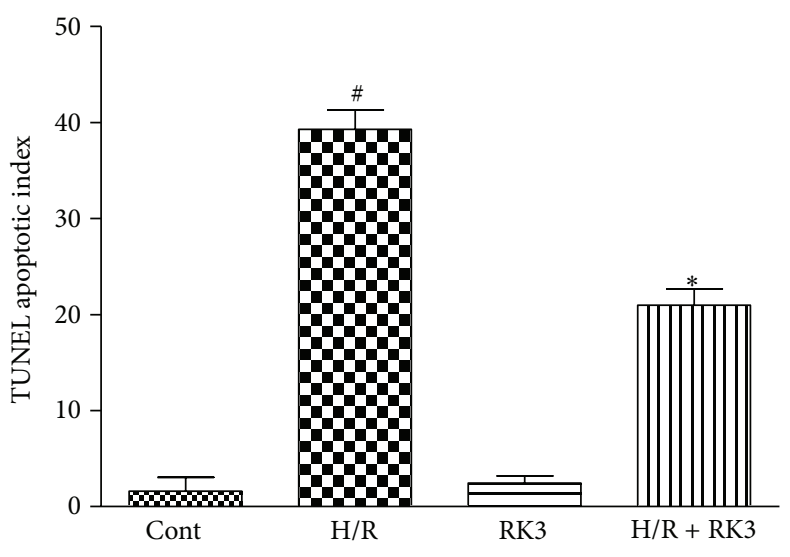

(b)

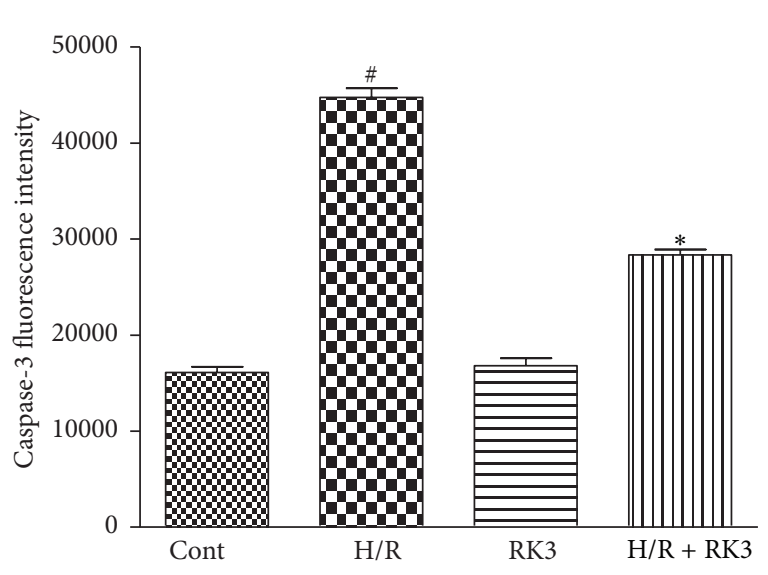

(c)

FIGURE 6: Effects of RK3 on apoptosis induced by H/R. H9c2 cardiomyocytes were pretreated with or without RK3 ( $25 \mu \mathrm{g} / \mathrm{mL})$ for $12 \mathrm{~h}$ prior to H/R exposure. The internucleosomal DNA fragmentation was determined by TUNEL assay (a). TUNEL apoptotic index was determined by calculating the ratio of TUNEL-positive cells to total cells (b). Caspase-3 activity (units per microgram of protein) was also assayed (c). The results are represented as means $\pm \mathrm{SD}$ from three independent experiments. ${ }^{\#} P<0.05$ versus control group; ${ }^{*} P<0.05$ versus $\mathrm{H} / \mathrm{R}$-treated cells.

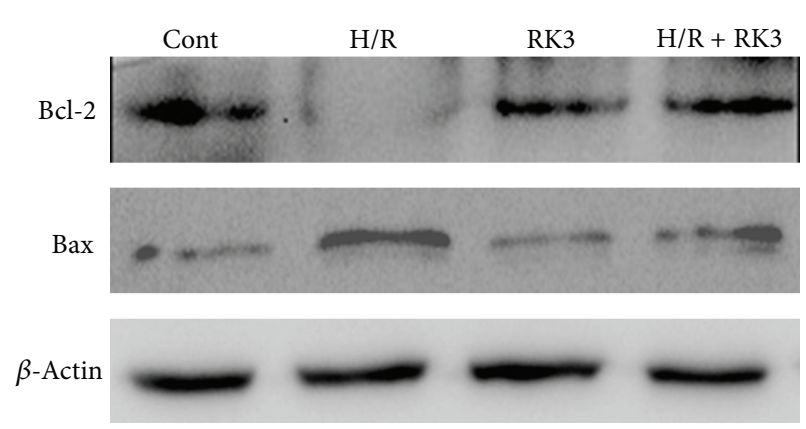

(a)

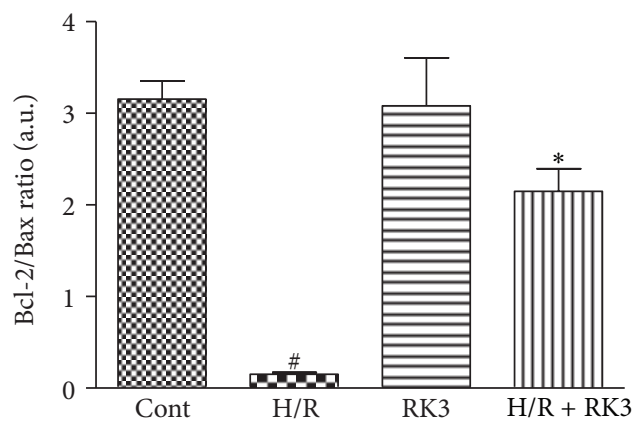

(b)

FIGURE 7: Effects of RK3 and H/R on expressions of Bcl-2 family proteins. The expression levels of Bcl-2 and Bax proteins were detected using an immunoblotting assay (a) and expressed as fold changes over the control (b). The results are represented as mean \pm SD from three independent experiments. ${ }^{\#} P<0.05$ versus control group; ${ }^{*} P<0.05$ versus $\mathrm{H} / \mathrm{R}$-treated cells. 


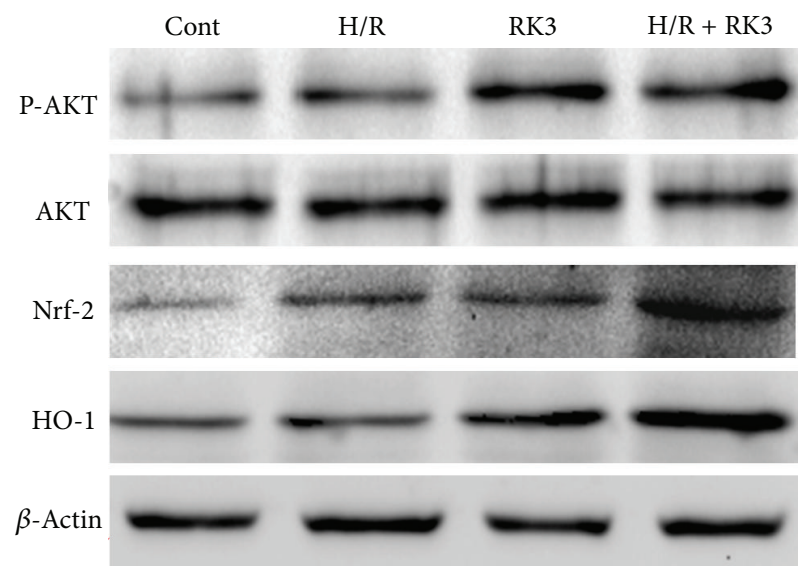

(a)

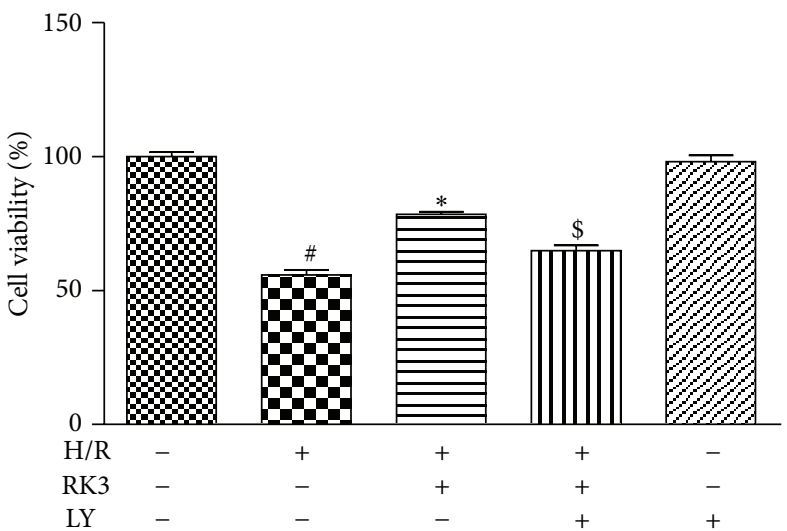

(c)

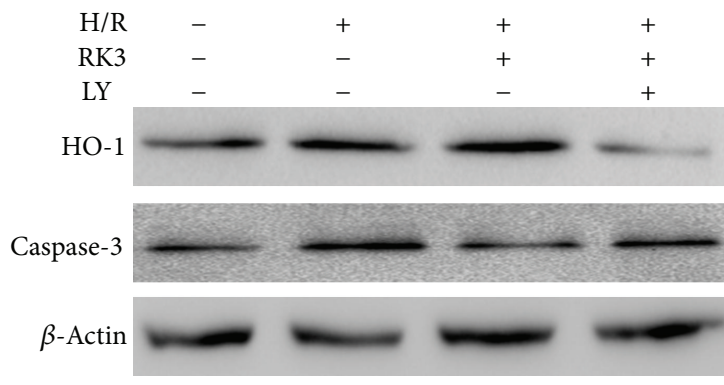

(b)

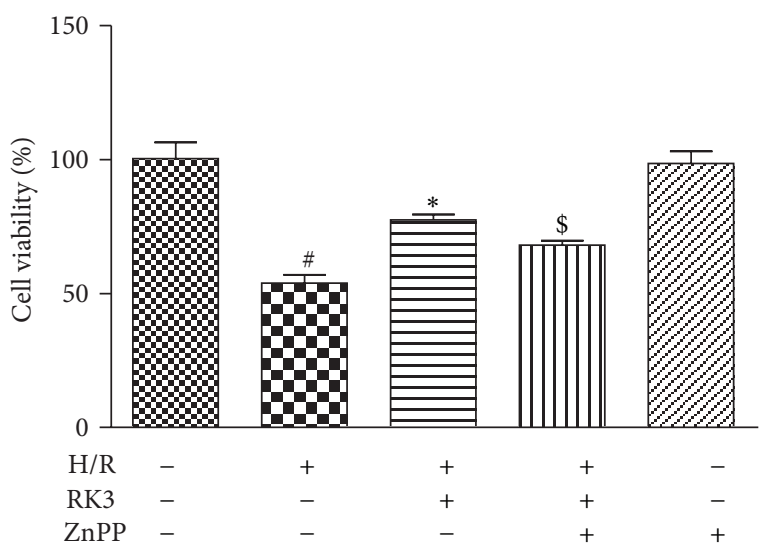

(d)

FIGURE 8: Involvement of AKT signaling transduction pathway and RK3 in H/R-induced caspase-3 activation and cytotoxicity. H9c2 cardiomyocytes were pretreated with or without RK3 $(25 \mu \mathrm{g} / \mathrm{mL})$ for $12 \mathrm{~h}$ prior to H/R exposure. The expression levels of ERK1/2, p38, and JNK activity were detected by immunoblotting assay (a). The effects of LY294002 (an AKT-specific inhibitor) on RK3-mediated activation of HO-1, caspase-3, and cell viability in H9c2 cardiomyocytes were measured (b and c). The effect of Znpp (an inhibitor of HO-1 activity) on RK3-mediated cardioprotection was also evaluated by CCK8 assay (d). The results are represented as means \pm SD from three independent experiments. ${ }^{\#} P<0.05$ versus control group; ${ }^{*} P<0.05$ versus $H / R$-treated cells; ${ }^{\$} P<0.05$ versus $H / R+R K 3$-treated cells.

In this sense, a time-dependent increase in the percentage of apoptotic cells was detected from $0 \mathrm{~h}$ to $24 \mathrm{~h}$ of reoxygenation in the model groups. This result suggests that apoptotic events occur in $\mathrm{H} 9 \mathrm{c} 2$ cardiomyocytes in response to hypoxia, and they are further evidenced by reoxygenation. The protective effect of RK3 pretreatment is manifested in the increased cell viability and decreased levels of LDH leakage. Moreover, RK3 pretreatment inhibited cell apoptosis, as evidenced by the decrease in caspase- 3 activity, TUNEL-positive cells, and Bax expression, as well as the increase in Bcl-2 level.

AKT and MAPK pathways are reportedly required for cell survival and apoptosis $[5,10]$. In this regard, we hypothesized that the cardioprotective effect of RK3 against H/R-induced apoptosis in H9c2 cardiomyocytes is related to a mechanism of AKT and MAPK signaling cascades. As expected, our results showed that RK3 treatment selectively increased the activation of AKT and ERK1/2 and inhibited the activity of JNK and p38. Thus, RK3 may suppress H/R-induced cell apoptosis, at least in part, through modulation of AKT and MAPK signaling pathways.
The PI3K/AKT pathway, a known target of I/R injury, plays a critical role in cell survival $[30,31]$. The influence of $\mathrm{H} / \mathrm{R}$ on the phosphorylation of AKT was first measured in this study. Western blot analysis showed that AKT phosphorylation was notably activated in H9c2 cardiomyocytes exposed to hypoxia and enhanced by reoxygenation. Pretreatment of RK3 increased the protein level of p-AKT significantly, compared with either the control group or the H/R group. Several studies demonstrate that AKT activation can activate $\mathrm{Nrf} 2$ and subsequently upregulate the expression of HO-1 [8, 32]. The activated Nrf2 is released from Keap1, which is the inhibitor of $\mathrm{Nrf} 2$, and translocates into the nucleus, where it binds to the antioxidant responsive elements (AREs) and accelerates HO-1 expression. HO-1, one of the phase II detoxification enzymes, was reported to play a key role in protecting against I/R induced injury [33]. Western blot results showed an increase in the protein level of Nrf2 in nuclear extracts after H/R. Pretreatment of RK3 enhanced the expression significantly compared with the H/R group. These results demonstrate that $\mathrm{RK} 3$ promoted the process of Nrf2 


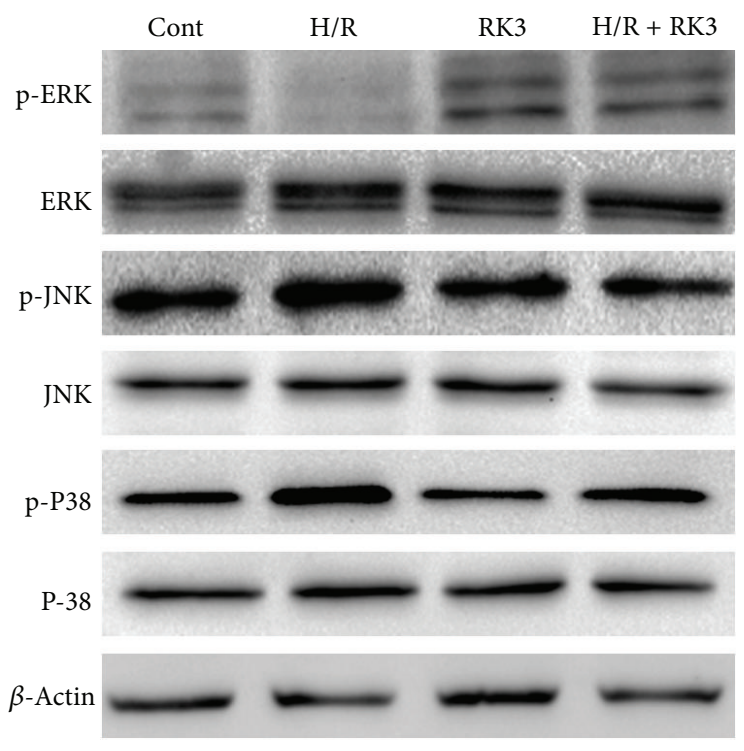

(a)

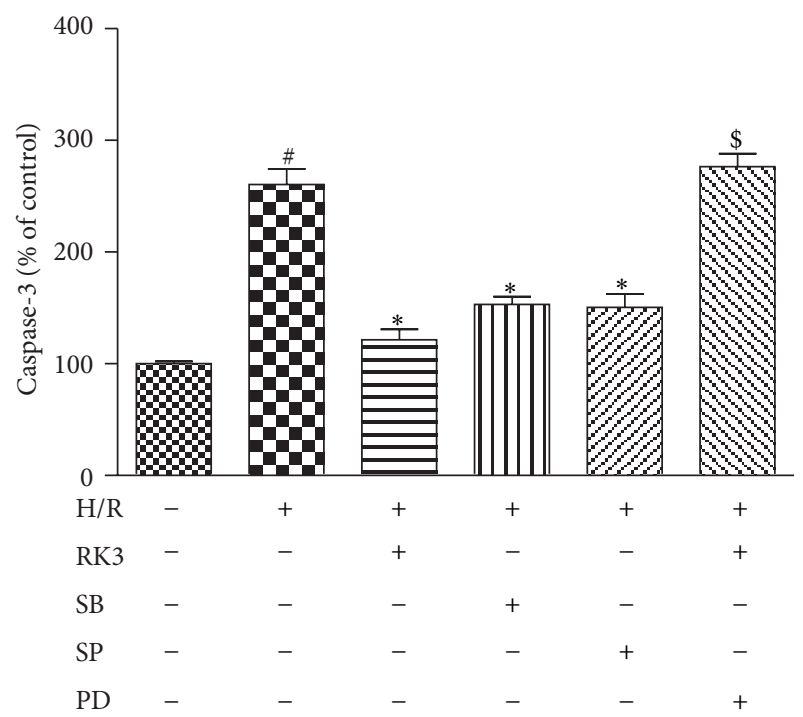

(c)

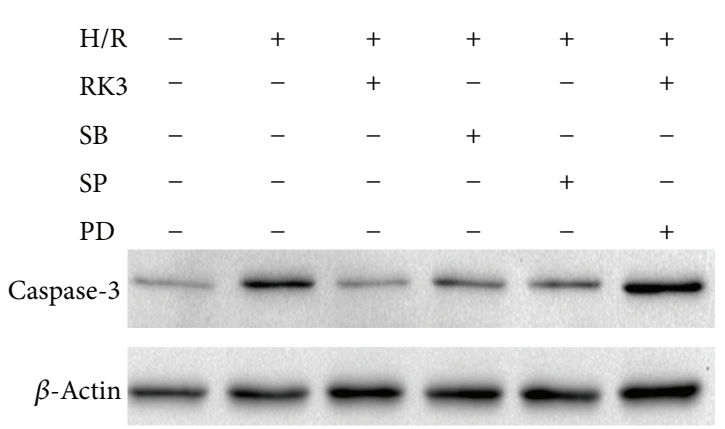

(b)

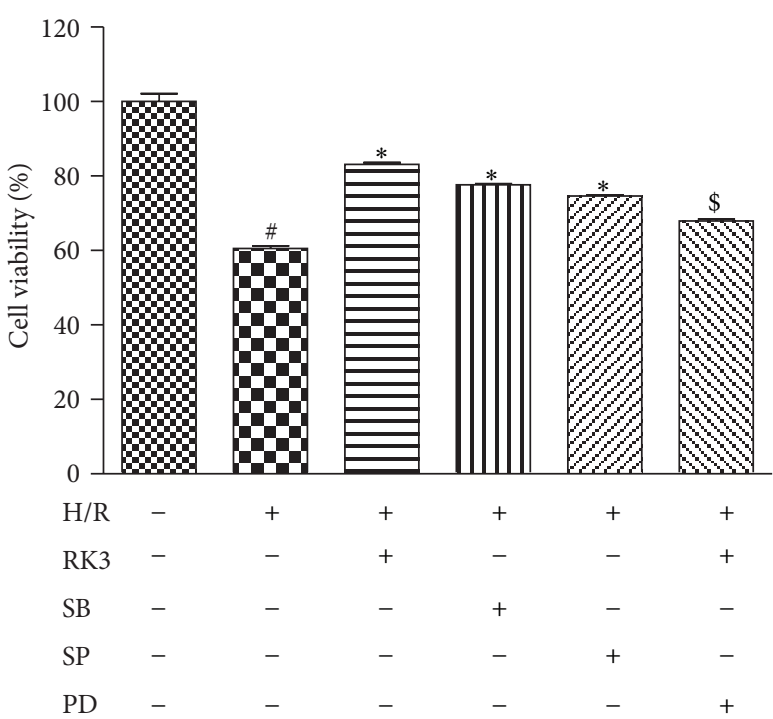

(d)

FIGURE 9: Involvement of ERK1/2, p38, JNK, and RK3 in H/R-induced caspase-3 activation and cytotoxicity. H9c2 cardiomyocytes were pretreated with or without RK3 $(25 \mu \mathrm{g} / \mathrm{mL})$ for $12 \mathrm{~h}$ prior to H/R exposure. The expression levels of phosphorylated and total ERK1/2, p38, and JNK were detected by immunoblotting assay (a). The effects of the PD98059 (an ERK1/2-specific inhibitor), SB203580 (a p38-specific inhibitor), and SP600125 (a JNK-specific inhibitor) on caspase-3 activation (b and c) and cell viability (d) were determined. The results are represented as means \pm SD from three independent experiments. ${ }^{\#} P<0.05$ versus control group; ${ }^{*} P<0.05$ versus H/R-treated cells; ${ }^{\$} P<0.05$ versus $\mathrm{H} / \mathrm{R}+\mathrm{RK} 3$-treated cells.

translocation into the nucleus. Accordingly, the expression of HO-1 in the H/R group was slightly upregulated, compared with the control group. Pretreatment of RK3 significantly enhanced the HO-1 upregulation in cardiomyocytes compared with the $\mathrm{H} / \mathrm{R}$ groups. It is worth noting that treatment of RK3 alone also has a positive effect on Nrf2 translocation and HO-1 upregulation. Furthermore, PI3K/AKT inhibitor LY294002 and HO-1 specific inhibitor ZnPP were used in this study to verify the PI3K/AKT/Nrf2/HO-1 pathway involved in the cardioprotective effect of RK3.
MAPK is a family of serine-threonine protein kinases that is activated in response to various extracellular stimuli, such as I/R injury. Three major subgroups of MAPK are found in mammalian cells: ERK1/2, JNK, and p38, which play key roles in cell growth, differentiation, and apoptosis. Among the MAPKs, JNK and p38 MAPK are preferentially activated in response to a variety of stresses and proapoptotic signals. By contrast, ERK1/2 preferentially responds to stimulation by growth-related signals and is reportedly associated with survival pathways against proapoptotic stimuli [11].Moreover, 
several reports demonstrate that JNK and p38 inhibition actually protects cardiac myocytes from I/R-induced apoptosis, whereas the inhibition of ERK1/2 is destructive to cardiomyocytes $[10,34,35]$. However, the role of the MAPK in apoptosis also remains controversial. Some reports indicated that upregulation of p38 activity during postinfarction LV remodeling rescued the failing myocardium. Further investigations showed that postinfarction LV remodeling and heart failure are characterized by a sustained downregulation of p38 kinase activity which is distinctly regulated from other cardiovascular diseases; therefore, we considered the effect of p38 dependents on different diseases and apoptotic stimuli [36].

Based upon the previous fact, the expressions of $\mathrm{p}$ ERK1/2, p-JNK, and p-p38 were determined at 0, 6, 12, 24, and $48 \mathrm{~h}$ after reoxygenation. The results showed that ERK1/2 was activated by $6 \mathrm{~h}$ of hypoxia and reduced after reoxygenation. However, JNK and p38 were significantly activated by hypoxia and persistently enhanced during the reoxygenation period. RK3 pretreatment selectively increased the expression of $\mathrm{p}$-ERK $1 / 2$ and decreased the upregulation of p-p38 and p-JNK. Moreover, treatment of cells with JNK inhibitor (SP98059) and p38 (SB203580) inhibitor alone significantly decreased the $\mathrm{H} / \mathrm{R}$-induced expression of cleaved caspase3 and the decline of cell viability. Furthermore, combined treatment with RK3 and ERK inhibitor (PD98059) attenuated the antiapoptotic effect mediated by RK3. Overall, these results indicate that the protective effect of RK3 against H/Rinduced apoptosis in $\mathrm{H} 9 \mathrm{c} 2$ cardiomyocytes partially relies on the inhibition of JNK and p38 and the activation of ERK1/2 signaling pathways.

In this study, the results show that pretreatment with RK3 can prevent H/R-induced apoptosis in H9c2 cardiomyocytes. This cytoprotection is manifested in the increased cell viability and decreased LDH leakage, caspase-3 activity, and TUNEL-positive cells, as well as in the downregulation of Bax expression and upregulation of $\mathrm{Bcl}-2$ protein. The underlying mechanisms of this protective effect of RK3 are connected with AKT and MAPK pathways.

In conclusion, these findings indicate that RK3 might act as a novel protective agent by inhibiting cardiomyocytes apoptosis in reperfusion therapy for AMI. In addition, RK3 is also a promising agent for the treatment of apoptosis-induced heart injury such as doxorubicine related cardiomyopathy and may have implications for other diseases associated with apoptosis, such as neurodegenerative disorders.

The limitation of this paper is that these results obtained from in vitro cell experiments needs to be verified in animal models. And the protective effect of RK3 should be confirmed in other apoptosis related disease models for expanding the applied range of RK3 in clinical field. Moreover, pharmacokinetic features of RK3 in animal and human also should be considered.

\section{Conflict of Interests}

The authors declare no conflict of interests.

\section{Acknowledgments}

The present work was supported by the Key Projects of the National Science and Technology Pillar Program (Grant no. 2008BAI51B02), National 973 Program (no. 2009CB522805), the Major Scientific and Technological Special Project for "Significant New Drugs Formulation" (Grant nos. 2012ZX09301002-001 and 2012ZX09501001-004), and Natural Science Foundation of Jiangsu Province, China (no. BK2010245).

\section{References}

[1] D. J. Hausenloy and D. M. Yellon, "Myocardial ischemiareperfusion injury: a neglected therapeutic target," Journal of Clinical Investigation, vol. 123, pp. 92-100, 2013.

[2] G. Olivetti, F. Quaini, R. Sala et al., "Acute myocardial infarction in humans is associated with activation of programmed myocyte cell death in the surviving portion of the heart," Journal of Molecular and Cellular Cardiology, vol. 28, no. 9, pp. 20052016, 1996.

[3] Z.-Q. Zhao, M. Nakamura, N.-P. Wang et al., "Reperfusion induces myocardial apoptotic cell death," Cardiovascular Research, vol. 45, no. 3, pp. 651-660, 2000.

[4] J. H. Jun, J. E. Cho, Y. H. Shim, J. K. Shim, and Y. L. Kwak, "Effects of propofol on the expression of matric metalloproteinases in rat cardiac fibroblasts after hypoxia and reoxygenation," British Journal of Anaesthesia, vol. 106, no. 5, pp. 650-658, 2011.

[5] C. Deng, Z. Sun, G. Tong et al., "Alpha-lipoic acid reduces infarct size and preserves cardiac function in rat myocardial ischemia/reperfusion injury through activation of PI3K/Akt/Nrf2 pathway," PLoS ONE, vol. 8, Article ID e58371, 2013.

[6] J. Chen, W. Wang, Q. Zhang et al., "Low molecular weight fucoidan against renal ischemia-reperfusion injury via inhibition of the MAPK signaling pathway," PLoS ONE, vol. 8, Article ID e56224, 2013.

[7] G. B. Sun, X. Sun, M. Wang et al., "Oxidative stress suppression by luteolin-induced heme oxygenase-1 expression," Toxicology and Applied Pharmacology, vol. 265, pp. 229-240, 2012.

[8] S.-X. Liu, Y. Zhang, Y.-F. Wang et al., "Upregulation of heme oxygenase-1 expression by hydroxysafflor yellow A conferring protection from anoxia/reoxygenation-induced apoptosis in H9c2 cardiomyocytes," International Journal of Cardiology, vol. 160, pp. 95-101, 2012.

[9] S. Lee, K. Kim, Y. H. Kim et al., "Preventive role of propofol in hypoxia/reoxygenation-induced apoptotic H9c2 rat cardiac myoblast cell death," Molecular Medicine Reports, vol. 4, no. 2, pp. 351-356, 2011.

[10] G. Vassalli, G. Milano, and T. Moccetti, "Role of mitogenactivated protein kinases in myocardial ischemia-reperfusion injury during heart transplantation," Journal of Transplantation, vol. 2012, Article ID 928954, 16 pages, 2012.

[11] S. W. Ryter, P. K. Hong, A. Hoetzel et al., "Mechanisms of cell death in oxidative stress," Antioxidants and Redox Signaling, vol. 9, no. 1, pp. 49-89, 2007.

[12] M. Stanciu and D. B. Defranco, "Prolonged nuclear retention of activated extracellular signal-regulated protein kinase promotes cell death generated by oxidative toxicity or proteasome inhibition in a neuronal cell line," Journal of Biological Chemistry, vol. 277, no. 6, pp. 4010-4017, 2002. 
[13] A. Das, F. N. Salloum, L. Xi, Y. J. Rao, and R. C. Kukreja, "ERK phosphorylation mediates sildenafil-induced myocardial protection against ischemia-reperfusion injury in mice," American Journal of Physiology, vol. 296, no. 5, pp. H1236-H1243, 2009.

[14] H.-Y. Sun, N.-P. Wang, M. Halkos et al., "Postconditioning attenuates cardiomyocyte apoptosis via inhibition of JNK and p38 mitogen-activated protein kinase signaling pathways," Apoptosis, vol. 11, no. 9, pp. 1583-1593, 2006.

[15] B. Sun, J. Xiao, X. B. Sun, and Y. Wu, "Notoginsenoside R1 attenuates cardiac dysfunction in endotoxemic mice: an insight into oestrogen receptor activation and PI3K/Akt signalling," British Journal of Pharmacology, vol. 168, pp. 1758-1770, 2013.

[16] Z. Wang, M. Li, W.-K. Wu, H.-M. Tan, and D.-F. Geng, "Ginsenoside Rb1 preconditioning protects against myocardial infarction after regional ischemia and reperfusion by activation of phosphatidylinositol-3- kinase signal transduction," Cardiovascular Drugs and Therapy, vol. 22, no. 6, pp. 443-452, 2008.

[17] D. Zhu, L. Wu, C.-R. Li et al., "Ginsenoside Rg1 protects rat cardiomyocyte from hypoxia/reoxygenation oxidative injury via antioxidant and intracellular calcium homeostasis," Journal of Cellular Biochemistry, vol. 108, no. 1, pp. 117-124, 2009.

[18] H. Wang, P. Yu, H. Gou et al., "Cardioprotective effects of 20(S)ginsenoside $\mathrm{Rh} 2$ against doxorubicin-induced cardiotoxicity in vitro and in vivo," Evidence-Based Complementary and Alternative Medicine, vol. 2012, Article ID 506214, 8 pages, 2012.

[19] D. N. Patel, H. S. Lin, and H. L. Koh, "Quantification of ginsenosides $\mathrm{Rh} 4$ and $\mathrm{Rk} 3$ in rat plasma by liquid chromatographytandem mass spectrometry: application to a pre-clinical pharmacokinetic study," Journal of Mass Spectrometry, vol. 47, pp. 1510-1517, 2012.

[20] D.-F. Toh, D. N. Patel, E. C. Chan, A. Teo, S.-Y. Neo, and H.-L. Koh, "Anti-proliferative effects of raw and steamed extracts of Panax notoginseng and its ginsenoside constituents on human liver cancer cells," Chinese Medicine, vol. 6, article 4, 2011.

[21] J. G. Lee, S. H. Baek, Y. Y. Lee, S. Y. Park, and J. H. Park, "Anticomplementary ginsenosides isolated from processed ginseng," Biological and Pharmaceutical Bulletin, vol. 34, no. 6, pp. 898900, 2011.

[22] J. G. Lee, Y. Y. Lee, B. Wu et al., "Inhibitory activity of ginsenosides isolated from processed ginseng on platelet aggregation," Pharmazie, vol. 65, no. 7, pp. 520-522, 2010.

[23] L. Feng, H. Meng, F. Wu et al., "Olfactory ensheathing cells conditioned medium prevented apoptosis induced by 6-OHDA in PC12 cells through modulation of intrinsic apoptotic pathways," International Journal of Developmental Neuroscience, vol. 26, no. 3-4, pp. 323-329, 2008.

[24] A. L. Moens, M. J. Claeys, J. P. Timmermans, and C. J. Vrints, "Myocardial ischemia/reperfusion-injury, a clinical view on a complex pathophysiological process," International Journal of Cardiology, vol. 100, no. 2, pp. 179-190, 2005.

[25] A. Abbate, G. G. L. Biondi-Zoccai, and A. Baldi, "Pathophysiologic role of myocardial apoptosis in post-infarction left ventricular remodeling," Journal of Cellular Physiology, vol. 193, no. 2, pp. 145-153, 2002.

[26] G. Takemura and H. Fujiwara, "Role of apoptosis in remodeling after myocardial infarction," Pharmacology and Therapeutics, vol. 104, no. 1, pp. 1-16, 2004.

[27] R. A. Gottlieb, K. O. Burleson, R. A. Kloner, B. M. Babior, and R. L. Engler, "Reperfusion injury induces apoptosis in rabbit cardiomyocytes," Journal of Clinical Investigation, vol. 94, no. 4, pp. 1621-1628, 1994.
[28] Y. Lv, X. Liu, S. Yan et al., "Metabolomic study of myocardial ischemia and intervention effects of Compound Danshen Tablets in rats using ultra-performance liquid chromatography/quadrupole time-of-flight mass spectrometry," Journal of Pharmaceutical and Biomedical Analysis, vol. 52, no. 1, pp. 129135, 2010.

[29] A. Florentin and E. Arama, "Caspase levels and execution efficiencies determine the apoptotic potential of the cell," Journal of Cell Biology, vol. 196, no. 4, pp. 513-527, 2012.

[30] D. L. Williams, T. Ozment-Skelton, and C. Li, "Modulation of the phosphoinositide 3-kinase signaling pathway alters host response to sepsis, inflammation, and ischemia/reperfusion injury," Shock, vol. 25, no. 5, pp. 432-439, 2006.

[31] M. G. Perrelli, F. Tullio, C. Angotti et al., "Catestatin reduces myocardial ischaemia/reperfusion injury: involvement of PI3K/Akt, PKCs, mitochondrial K(ATP) channels and ROS signalling," Pflügers Archiv, vol. 15, article 15, 2013.

[32] Y. M. Ha, M. Y. Kim, M. K. Park et al., "Higenamine reduces HMGB1 during hypoxia-induced brain injury by induction of heme oxygenase-1 through PI3K/Akt/Nrf-2 signal pathways," Apoptosis, vol. 17, no. 5, pp. 463-474, 2012.

[33] B. Juhasz, B. Varga, A. Czompa et al., "Postischemic cardiac recovery in heme oxygenase-1 transgenic ischemic/reperfused mouse myocardium," Journal of Cellular and Molecular Medicine, vol. 15, no. 9, pp. 1973-1982, 2011.

[34] P. Xie, S. Guo, Y. Fan, H. Zhang, D. Gu, and H. Li, "Atrogin$1 / \mathrm{MAFbx}$ enhances simulated ischemia/reperfusion-induced apoptosis in cardiomyocytes through degradation of MAPK phosphatase-1 and sustained JNK activation," Journal of Biological Chemistry, vol. 284, no. 9, pp. 5488-5496, 2009.

[35] Z. Wang, M. Zheng, Z. Li et al., "Cardiac glycosides inhibit p53 synthesis by a mechanism relieved by Src or MAPK inhibition," Cancer Research, vol. 69, no. 16, pp. 6556-6564, 2009.

[36] O. Tenhunen, Y. Soini, M. Ilves et al., "p38 Kinase rescues failing myocardium after myocardial infarction: evidence for angiogenic and anti-apoptotic mechanisms," The FASEB Journal, vol. 20, no. 11, pp. 1907-1909, 2006. 


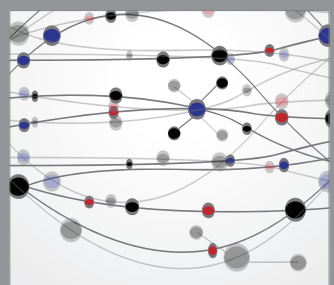

The Scientific World Journal
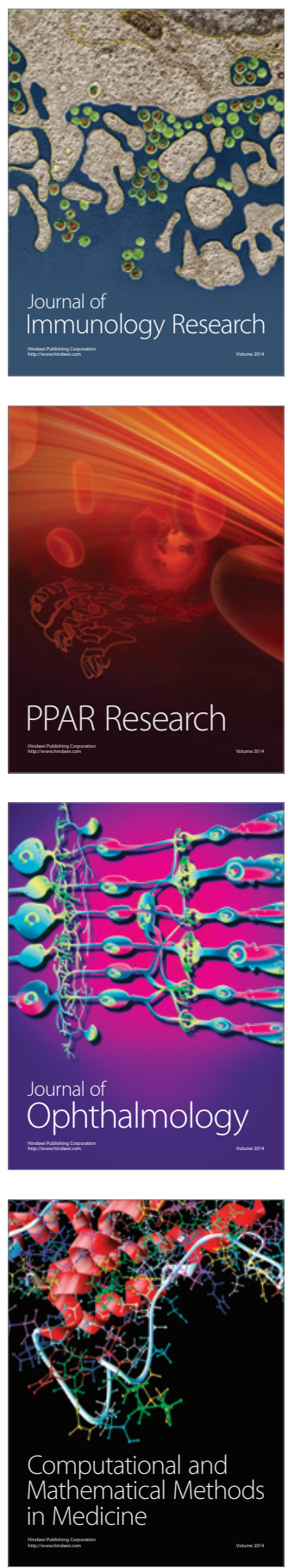

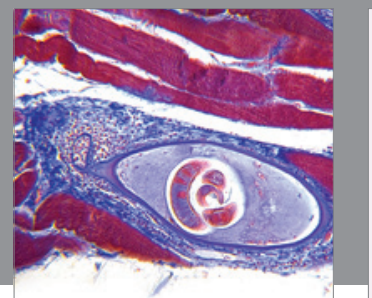

Gastroenterology

Research and Practice
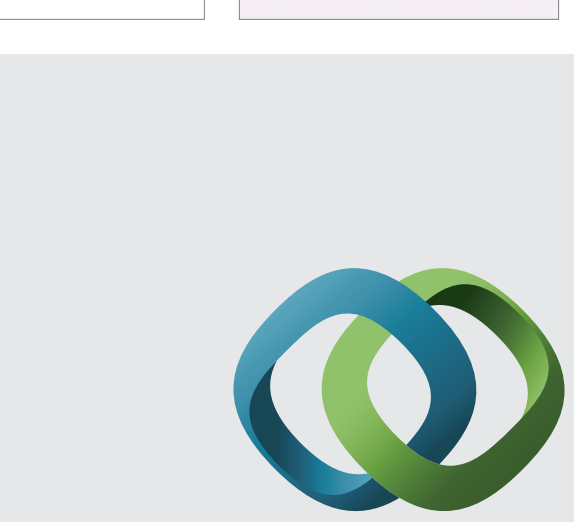

\section{Hindawi}

Submit your manuscripts at

http://www.hindawi.com
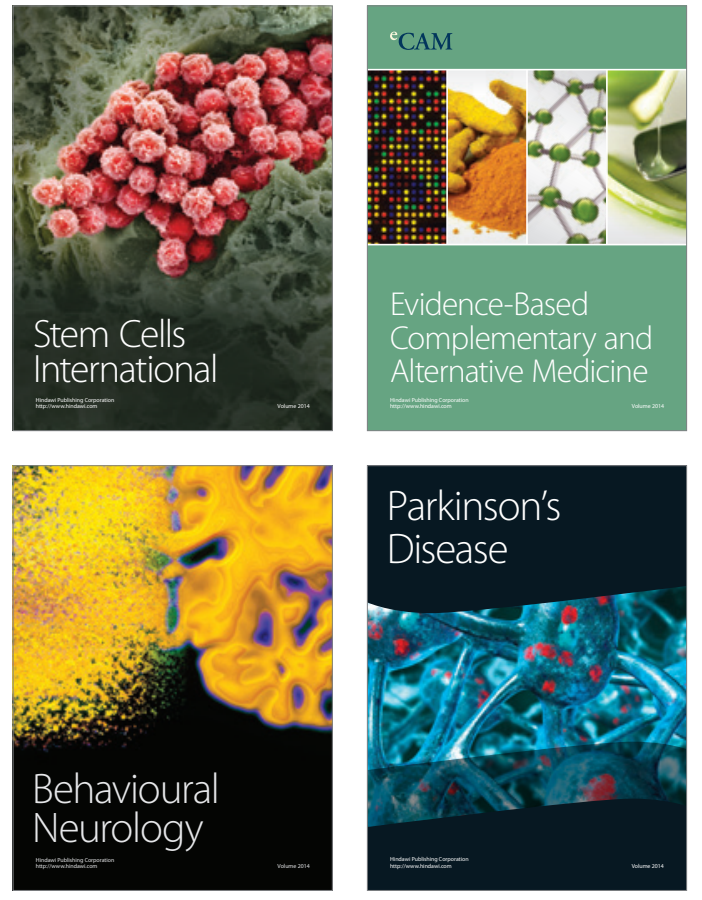
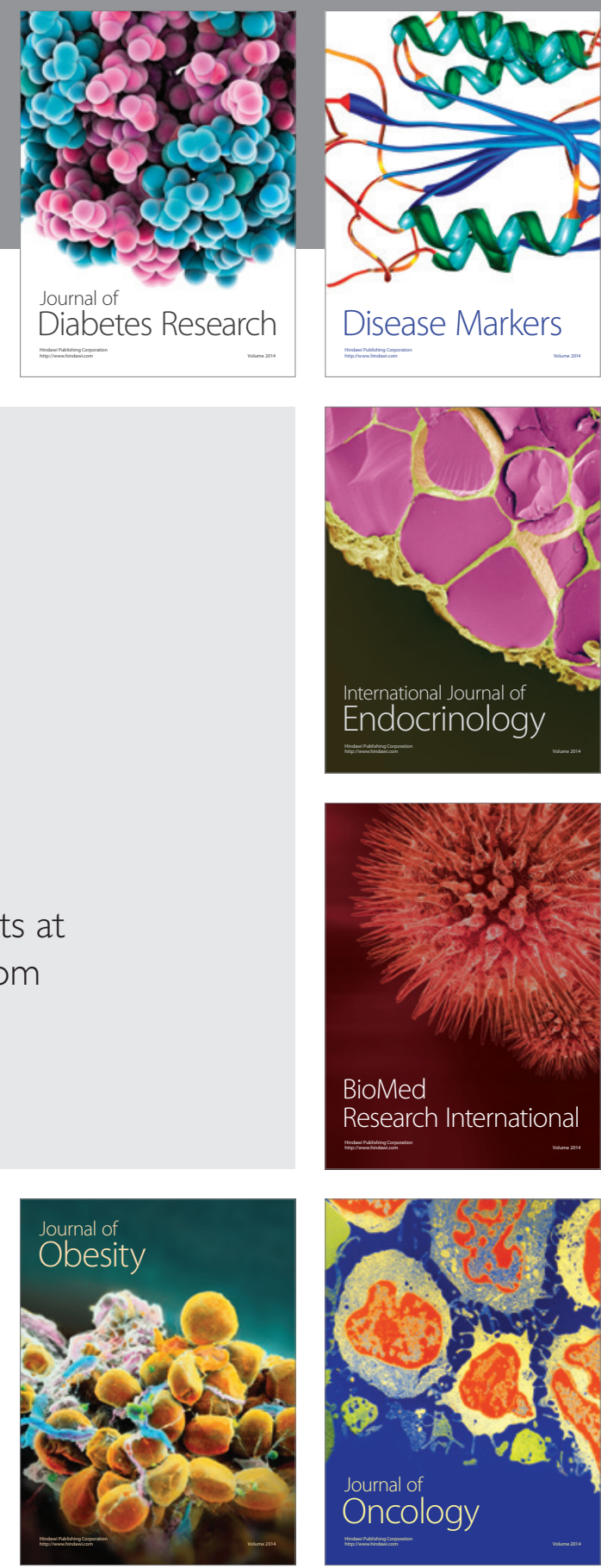

Disease Markers
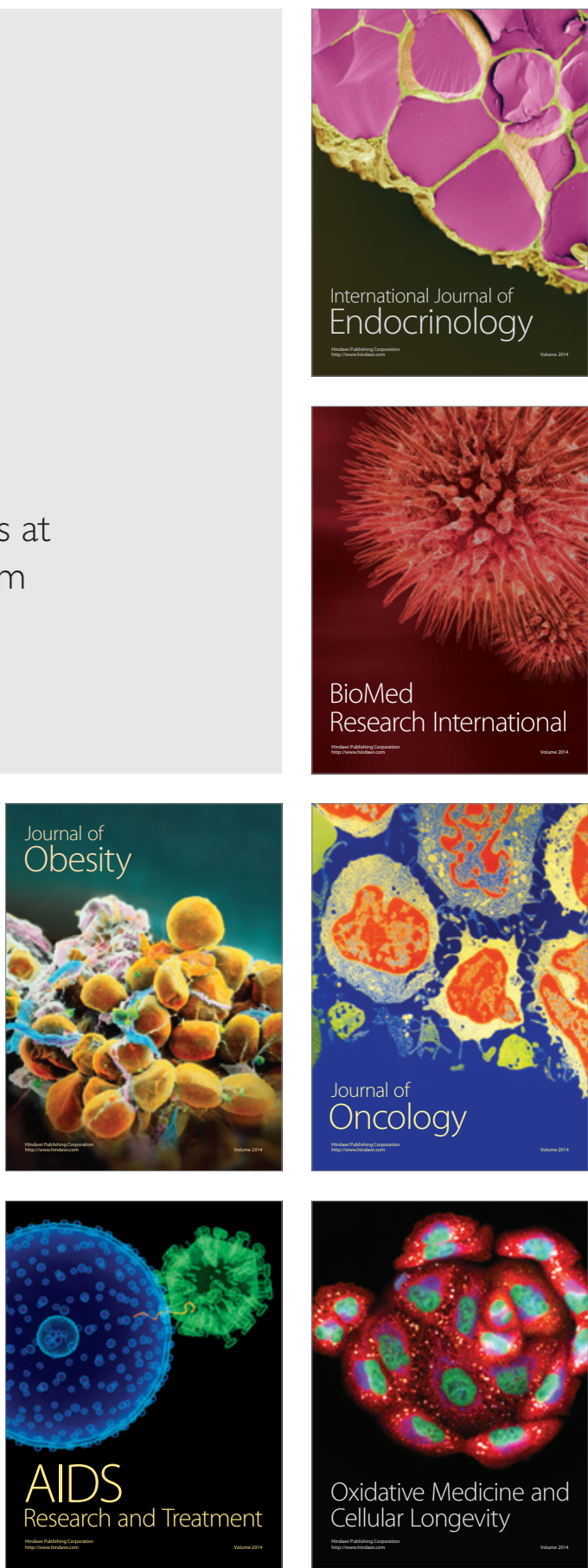